\title{
EDUCACIÓN AMBIENTAL (EA), FORMACION DOCENTE Y TIC'S, EL DESAFÍO COMPLEJO DE UNA TRIPLE ARTICULACIÓN. HACIA LA DEFINICIÓN DE UN ESPACIO TRANSVERSAL (1)
}

\author{
Silvina Corbetta (Universidad Nacional del Comahue - \\ Escuela "Marina Vilte" de CTERA)* \\ silvina_corbetta@yahoo.com.ar \\ Pablo Sessano (Universidad de Buenos Aires)** \\ refractario@yahoo.com \\ Mariano Krasmanski (Universidad de Buenos Aires) $)^{* * *}$ \\ marianokrass@gmail.com
}

Recibido: 28/07/2012 Aceptado: 9/10/2012

\section{Resumen}

Desde que los problemas ambientales irrumpieron en la educación es difícil determinar por qué un tema deviene "ambiental", qué significa, dónde empieza y terminan sus dimensiones, quién se hace cargo de explicarlo o cómo se tramita en la enseñanza. La educación atraviesa la insuficiencia de los enfoques disciplinares para responder integralmente a estos "desafíos de comprensión" en un contexto planetario donde la sociedad está en vertiginoso cambio. Por otra parte, las Tic's están revolucionando la percepción y su incorporación al ámbito educativo habilita otras formas de inteligir el universo natural y social. Así, los problemas ambientales, como las Tic's "desafían" la forma en que los científicos y profesores hemos sido formados. Argentina prácticamente no posee políticas públicas de educación ambiental (EA) y

* Especialista en Educación Ambiental para el Desarrollo Sustentable (UNComa-M.Vilte). Lic. en Ciencia Política. Universidad de Buenos Aires. Investigadora de UNIPE y capacitadora en Conectar Igualdad-Escuelas de Innovación.

** Especialista en Planificación del Medio (IIE-UICIN), en Gestión y Análisis de Políticas Ambientales (INAP-México), y en Gestión Ambiental Metropolitana. (Fadu-UBA). Investigador del Instituto Investigaciones en Ciencias de la Educación (FFyL-UBA)

${ }^{* * *}$ Maestro Nacional de Bellas Artes. Secretaria de Extensión Universitaria-Facultad de Ciencias Económicas-Universidad de Buenos Aires. Equipo de Educación Ambiental Proyecto Escuelas de Innovación-Conectar Igualdad. 
en el marco de las recientes políticas educativas destinadas a minimizar la brecha tecnológica, la EA no es un contenido prioritario. Ante este escenario elaboramos la presente propuesta de articulación de EA y Tic's -vacante uno, en desarrollo el otro- como un espacio transversal de formación docente que permita la confluencia de perspectivas para tramitar pedagógicamente la complejidad inherente al contexto descrito e inaugurar una mirada híbrida e interdisciplinar en el abordaje de temas ambientales en los espacios educativos.

\title{
Palabras clave
}

Educación ambiental - TIC - Desafíos de comprensión - Disciplinas híbridas Transversalidad.

\begin{abstract}
Since the environmental problems burst into the education, is difficult to determine why a topic becomes "environmental", what it means, where its dimensions start and finish, who takes charge of explain it, or how to process it into the education. Education passes through the insufficiency of the disciplinary approaches to respond fully to these "challenges of understanding" in a context where the planetary society is rapidly changing. On the other hand, the ICT's are revolutionizing the perception and its incorporation into the field of education enables other forms of inteligir the natural universe and social. In this way, environmental problems, like as icts "defy" the way in which scientists and teachers we have been was educated. In Argentina and in the context of the recent educational public policy aimed at minimizing the technology gap, the EA is not a priority content. In this scenario we developed this proposal of articulation of EA and ICT's -vacancy one, developing another - as a space of cross training teacher, which allows the confluence of prospects for dealing with pedagogically the inherent complexity of the described context and to inaugurate a hybrid and interdisciplinary look at the approach of environmental issues in educational spaces.
\end{abstract}

\section{Key words}

Environmental education - ICT - Challenges of understanding - Hybrid disciplinesTransversality.

\section{Introducción}

Desde que los problemas ambientales han irrumpido como tales, en el mundo en general y en la educación en particular, sigue siendo difícil e impreciso, determinar por qué un tema se convierte en "ambiental", qué significa ello, dónde empieza y terminan las dimensiones biológicas, físicas, técnicas, sociales o culturales del problema, quién se hace cargo de explicarlo y comunicarlo, en definitiva cómo se tramitan estos temas que han devenido contenidos significativos en la enseñanza.

La escuela actual atraviesa, igual que las demás instituciones de los distintos niveles educativos, la dificultad o insuficiencia de los enfoques disciplinares 
para responder satisfactoriamente e integralmente, a este tipo de problemas que se transforman en verdaderos "desafíos de comprensión", en un contexto planetario donde la sociedad toda está en un cambio permanente y vertiginoso (2). De este modo, los problemas ambientales, como las TICs, aparecen "desafiando" en cada institución educativa la forma en que los profesionales de las ciencias y los profesores hemos sido formados. Es dable pensar que las TiCs encontrarán finalmente, más temprano que tarde, el modo de articularse en y con la enseñanza escolar, dando lugar a "nuevos entornos de aprendizaje" aggiornados tecnológicamente. Pero no es seguro que tal integración resulte en un cambio profundo en la manera de concebir el mundo, especialmente la relación que la humanidad, ha construido con la naturaleza. Este cambio de perspectiva supone un posicionamiento diferente frente al conocimiento y el reconocimiento de que las formaciones disciplinares no alcanzan a dar respuesta a los problemas complejos que plantea esta relación, por el simple hecho de que los problemas de los investigadores no se presentan en la realidad clasificados por disciplinas (Toledo, Alarcón Chaires, Barón, 2002). Creemos que las TICs colaborarán seguramente a este cambio de perspectiva, pero no por sí mismas ni automáticamente, sino en un proceso que oriente su funcionalidad hacia esa finalidad.

En adelante, desarrollaremos una propuesta de capacitación docente en Educación Ambiental (EA) que aunque incipiente aún, permite delinear una dirección conceptual-metodológica, unos objetivos y una didáctica de trabajo como un ejercicio posible a la hora de relacionar educación ambiental y TICs en la escuela.

\section{Aproximación a un marco conceptual en EA}

El ambiente es el resultado de la forma particular en que la sociedad moderna y la naturaleza se han relacionado, asumiendo una escisión de origen que se expresa en la diferencia sujeto/objeto, la correlativa relación de fuerza expresada en la supremacía de la sociedad sobre la naturaleza y finalmente, las consecuentes formas de apropiación desigual del mundo y sus formas dominantes de conocimiento; expresadas en este caso, en la fragmentación del saber para conocer "ese mundo".

Vista la definición de ambiente desde el paradigma de la modernidad, resultará más fácil exponer por qué concebimos los problemas ambientales como "desafíos de comprensión". Efectivamente, los problemas ambientales o bien, los temas que involucran aspectos múltiples de la relación entre la sociedad industrialista (que es la que la humanidad moderna ha construido) y la naturaleza, tienen origen en un particular modo de comprender el mundo y generar conocimiento sobre el mismo. Es decir, en primer lugar, el mundo de la modernidad surge escindido, separado, producto de una concepción que fractura a la sociedad (sujeto) de la naturaleza (objeto), con la consecuente 
supremacía de la primera sobre la segunda. Esta escisión lleva a comprender la "naturaleza" como un simple objeto de apropiación humana, a la que hay que conocer para dominar. La condición cartesiano-positivista (y darwinista) del modelo de conocimiento que hegemoniza la educación en la modernidad es uno, sino el mayor, de los obstáculos para tramitar otra forma de comprensión de esta relación. La cuestión remite a un cambio de paradigma.

En segundo lugar y producto de la escisión de origen, surge la fragmentación del saber convirtiéndose en la mayor expresión de ese mundo moderno escindido. Es decir, para abordar analíticamente el mundo por partes se procede a fragmentar el conocimiento entre ciencias sociales y ciencias de la naturaleza que a su vez se fragmentan interiormente entre disciplinas, ramas y especialidades. Según palabras de Edgar Morin (1999),

(...) la supremacía de un conocimiento fragmentado según las disciplinas impide a menudo operar el vínculo entre las partes y las totalidades y debe dar paso a un modo de conocimiento capaz de aprender los objetos en sus contextos, sus complejidades, sus conjuntos. (Morin, 1999, p. 2)

Desde la perspectiva de Fritjof Capra (2007) el desarrollo de una dinámica no-lineal, que en los años '70-' 80 se conoce de manera general como teoría de la complejidad, marca para el autor un cambio en la comprensión de los sistemas vivos. Un nuevo lenguaje con conceptos clave como caos, atractores, fractales, bifurcaciones aparecen en escena, y son otras preguntas las que debemos formularnos cuando tratamos con sistemas no lineales, como lo son la naturaleza y la sociedad, y mucho más cuando el sistema lo constituye su relación. Para Capra, esto produjo algunos descubrimientos significativos en nuestra comprensión de la vida que demanda un marco conceptual integrativo de tres dimensiones: la biológica, la cognitiva, y la social. Es decir, el estudio de la naturaleza, el estudio del conocimiento y el estudio de la sociedad. Así:
(...) las cuestiones sociales principales -salud, educación, derechos humanos, justicia social, poder político, protección del medioam- biente, gestión empresarial, economía, etc.- todas tienen que ver con los sistemas vivos: con los seres humanos individuales, con los sistemas sociales y con los ecosistemas (Capra, en CERN, 2007, p. 15)

Frente a todo esto Morin (1999) afirma que es indispensable desde los ámbitos de la enseñanza "desarrollar la aptitud natural de la inteligencia humana para ubicar todas sus informaciones en un contexto y en un conjunto" (Morin, et.al: 15). Esto significa que no sólo se requiere de la enseñanza de métodos que nos permitan aprehender las mutuas relaciones entre las partes y el todo, 
en un mundo que es complejo, sino de la necesidad de una evolución cognitiva dirigida hacia la contextualización del saber.

Visto así, cabe remarcar dos aspectos de la ambiciosa propuesta de Morin y Capra, la idea de aptitud natural de la inteligencia humana para la complejidad y la idea de un marco conceptual integral o integrado que implica, por un lado; diálogo entre disciplinas o entre saberes científicos y por otro, diálogos entre saberes expertos y no expertos; adicionando a la integración de saberes disciplinares la dimensión participativa de la ciudadanía.

Rolando García (1994), a propósito del debate sobre la complejidad, interdisciplina o transdisciplina, propuso hace años, especialmente en relación con los temas de ambiente, la idea de reconstruir los objetos de estudio partiendo del aporte integrado de las miradas disciplinares, lo cual conduce de la pluri o multidisciplina a la interdisciplina. También Silvio Funtowicz junto a otros colegas (1993) (2000), han pensado en este sentido, proponiendo que la ciencia evoluciona en la medida en que es capaz de responder a los principales desafíos de cada época. Los de la nuestra conciernen al riesgo ambiental global y a la equidad entre los pueblos y la reorientación de la finalidad científico-tecnológica.

Como respuesta a éstos ya están en desarrollo nuevos estilos de actividad científica, con diferentes grados de integración y valoración de recursos tecnológicos, en este sentido desde la literatura se argumenta que es el propio dinamismo y complejidad de los problemas lo que obliga a concebir una ciencia cuya base tiene como atributos la impredictibilidad, el control incompleto y la necesaria participación de una pluralidad de perspectivas legítimamente reconocidas. Todo esto bajo la evidencia de que no existe ninguna tradición cultural que haya podido prever por sí sola todas las respuestas que exigen los problemas del planeta. El único modo de abordar los nuevos problemas ambientales globales, tiene que ver con la construcción de una metodología de investigación (una ciencia) que sea apropiada para las condiciones contemporáneas. Cuando los factores son inciertos, hay valores en disputa, los riesgos son altos y las decisiones urgentes, sólo una "comunidad de pares extendida", compuesta por todos aquellos afectados por un tema en concreto, estarán preparados para entrar en un diálogo y tener posibilidades de arribar a soluciones (Funtowicz y Ravetz, 1993).

Entendemos pues, que la fragmentación es resultado de una tradición de construcción del conocimiento pero en modo alguno el "único modo" de tramitarlo. Consecuentemente una propuesta de EA debe enfocarse hacia la construcción de un dispositivo que tienda a dar lugar, mediante el trabajo interdisciplinar, a la hibridación de las perspectivas, con el objetivo de abrir un camino de comprensión más adecuado para los desafíos de la época. Estos primeros señalamientos servirán de marco teórico básico para justificar, definir y contextuar la centralidad transversal que proponemos para los temas de la EA, tanto en el proceso de actualización de los contenidos y métodos como 
en la integración de TICs al sistema educativo y la formación docente. Desde esta perspectiva de EA tiene un rol fuertemente ético y las TICs no deben ser integradas al proceso educativo irreflexivamente sino más bien deben ayudar a romper la lógica que han generado los problemas ambientales contemporáneos.

\section{La educación ambiental (EA), los temas o "problemas ambientales". Hacia una definición del campo de trabajo}

Distingamos primero entre temas de la enseñanza de la EA y temas o problemas ambientales. Los primeros se refieren precisamente a las categorías requeridas para tramitar la EA, algunas de las antes señaladas, fundamentalmente complejidad, interdisciplina (transdisciplina) y transversalidad. Visto así los temas de la enseñanza de la EA son de orden fuertemente epistemológicos. Los segundos se refieren concretamente a ciertos temas prexistentes en los contenidos de la enseñanza y temas que emergen como "problemas" en el marco de la transformación de la relación sociedad/naturaleza en los últimos 50 años, ambos temas devenidos significativos (3) en términos de la educación en el presente. Para establecer los alcances de la "EA" y de los "temas o problemas ambientales" se puede acudir a la profusa literatura producida desde el campo del pensamiento ambiental y la complejidad (4). Para este caso, tomamos a Víctor Toledo, Pablo Alarcón Chairés y Lourdes Barón (2002) que sostienen que en la práctica lo que llaman la "superación del parcelamiento cognitivo", se viene dando desde hace tiempo, pero

(...) no como procedimiento autoconsciente de los investigadores sino como una manera espontánea, multipolar y asincrónica, es decir ha surgido en diferentes momentos y en los diversos campos del conocimiento, ahí donde los propios problemas han inducido la creación de nuevos enfoques integradores. (Toledo y otros, 2002, p. 9).

Dirán después que un ejemplo concreto de problemas que inducen a esta resolución son los problemas ambientales. Por ende, la mejor manera de abordar esos problemas, describirlos, interpretarlos y sobre todo resolverlos es a través de "enfoques integrativos". Estos autores sostienen que justamente como respuesta a la problemática ambiental se ha gestado una veintena de "disciplinas híbridas", denominando así a las formas interdisciplinarias de abordar la realidad "en que el enfoque implementado resulta de la integración del estudio sistémico de la naturaleza (ecología) con diferentes enfoques dedicados a estudiar el universo social" (Toledo, Alarcón Chaires, Barón, 2002, p. 9). 


\section{Figura 1. El surgimiento de las disciplinas híbridas}

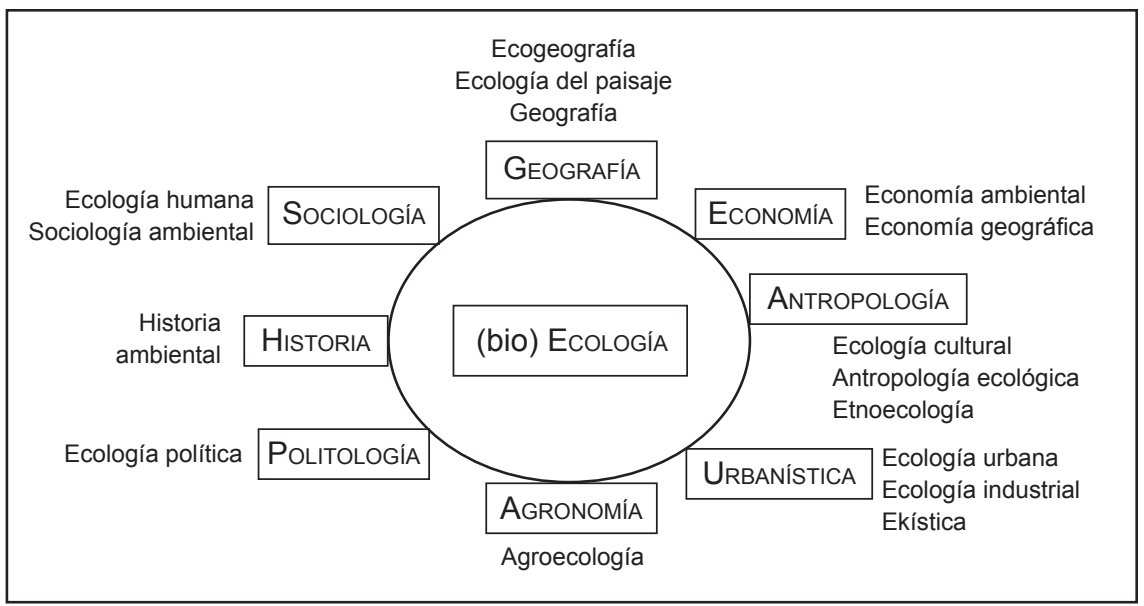

Fuente: Toledo, Alarcón Chairés y Barón (2002) [5]

En el esquema que sigue, se representan los campos tradicionales del conocimiento del mundo; la sociedad y la naturaleza y, en su intersección, la forma interdisciplinar que origina a posteriori, la búsqueda de respuestas a la problemática ambiental:

\section{Figura 2:}

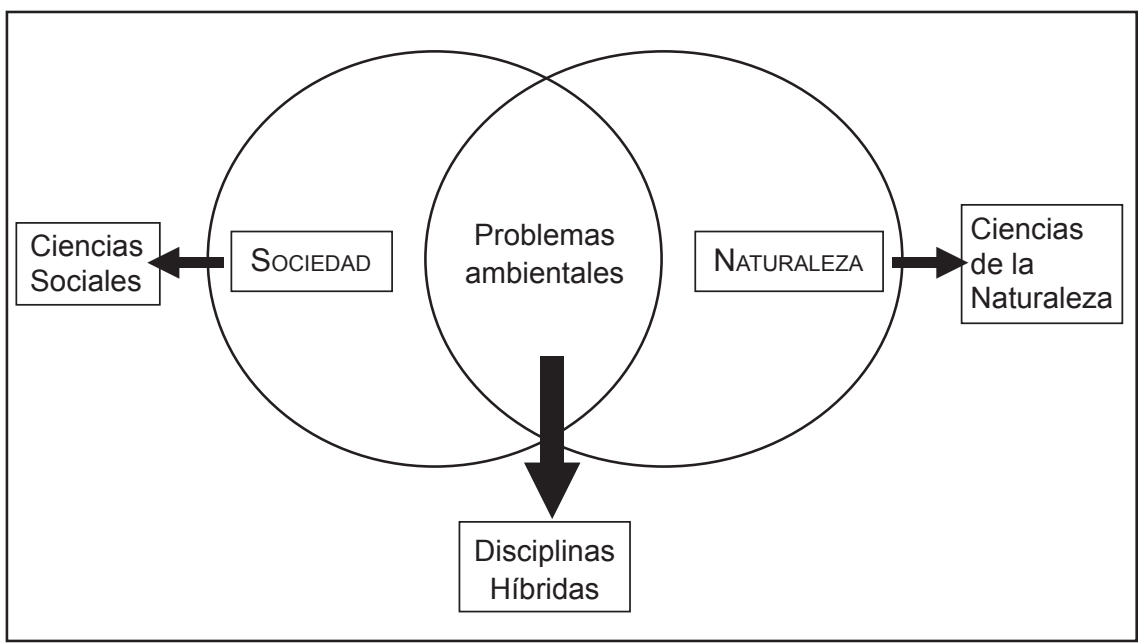

Fuente: Elaboración propia. 
Las formas interdisciplinares o las disciplinas hibridas demuestran según los mencionados autores, que la heterogeneidad es el rasgo principal de la fertilización recíproca entre disciplinas. Coincidiendo con este enfoque sostenemos que la EA es y debe ser una forma híbrida traducible en un esfuerzo transversal por abordar de forma integrativa los temas o las "problemáticas ambientales" desde el espacio escolar. Es decir, la EA, en tanto campo transversal del conocimiento, no entrará en competencia con temas específicos de áreas disciplinares sino más bien trabajará problematizando la intersección entre disciplinas y enfoques. En definitiva, posicionará su campo de acción en la intersección entre sociedad y naturaleza; lugar mismo donde se sitúa la dificultad de las ciencias para abordar esa relación de forma integral.

Todo esto, sin dejar de considerar los fundamentos éticos y las diversidades culturales que están en juego, en los distintos modos de percibir la naturaleza. Las disputas de sentidos que se desprenden de matrices culturales diferentes a la hora de valorarla, se dimensionan concretamente, en los distintos territorios donde los conflictos ambientales tienen lugar. La EA puede restituir en ese sentido, al proceso mismo del conocimiento, una dimensión axiológica, allí cuando a menudo las diferentes concepciones de los actores en pugna, conllevan a una disputa desigual por los recursos. Si nos detuviéramos sobre estas ideas deberíamos recoger por lo menos dos aportes, los que provienen desde la ética ecológica y los que provienen desde el saber ambiental, la ciudadanía ambiental y la economía ambiental.

Desde la ética ecológica, Nicolás Sosa (1991) sostenía que si la EA, de verdad quiere dar respuesta global a problemas que también son globales, ha de orientarse en el sentido indicado de educar "en una percepción distinta de la realidad". Según expresa este autor, es tiempo de "cruzar umbrales de percepción". En parte el problema se origina por el modo en que la humanidad percibe sus relaciones con los sistemas naturales de la tierra, por ende para dar respuesta a problemas como el calentamiento del planeta, el crecimiento demográfico, la persistente incidencia de la pobreza en el mundo, la desigualdad intrasocietaria e intraplanetaria... "es necesario un profundo cambio perceptivo". Tales cambios de percepción suelen presentar a su parecer, "un componente claramente ético, porque están vinculados a pautas arraigadas de comportamiento, creencias y valores. Y son requisitos previos para la puesta en práctica de medidas efectivas" (Sosa, 1991, p. 478).

En este sentido, coincidimos en que el rol de la educación ambiental es de orden ético.

(...) Las razones más poderosas para decidir cambiar un modo de vida son las razones de tipo ético y en este terreno, las decisiones morales las toma el individuo; pero las bases teóricas, la información, los argumentos, etc., las aporta el educador (Sosa, 1991, p. 477). 
En el horizonte de la ética ecológica que Sosa propone está la "Comunidad utópica" -donde prevalece la justicia, la solidaridad y la cooperación ecológica. Algo muy importante de resaltar es que esa Comunidad Utópica no es una comunidad integrada solamente de humanos, sino de humanos y su medio. El autor consideraba indispensable una educación ambiental que divulgue una ética ecológica capaz de admitir el cuestionamiento global de la práctica humana en el mundo. Una ética ecológica cuyo pilar sea el de la "solidaridad ecológica"; solidaridad entre seres humanos y de estos para con el resto de las especies con las que compartimos el planeta. En estos términos el problema que ha de ser pensado, no es ya el de "hombre y naturaleza" sino el hombre en la naturaleza.

A su vez, resulta complementario el enfoque de construcción de ciudadanía o ciudadanía ambiental. En esta dirección es importante retomar a Enrique Leff (2002) cuando define al ambiente como el campo de o la resultante de las relaciones entre la naturaleza, la sociedad y la cultura o si se prefiere, los sistemas natural, social y cultural, incluidos los aspectos materiales y simbólicos. Es así que la complejidad del ser y del pensamiento actúan como fuerzas en la apropiación del mundo desde relaciones de poder que se han inscrito en formas dominantes del conocimiento.

En el contexto latinoamericano estas relaciones de poder y formas dominantes del conocimiento adquieren una configuración (sociohistórica) particular y seguramente podremos reconocer que una de las principales contribuciones a la ampliación y complejización de sentido sobre lo ambiental, el ambiente y la EA, proviene no sólo del ámbito académico, sino sobre todo del ejercicio de interpelación socio-política que la sociedad civil viene realizando con creciente intensidad respecto del poder, la democracia y los problemas ambientales (González Gaudiano, 2007) (Sessano, 2011) (Sessano, 2012) [6] [7],. Visto así, la crisis ambiental es síntoma de la crisis social en general, crisis de instituciones políticas, aparatos jurídicos, relaciones sociales y racionalidad científica (Manifiesto por la Vida, 2002). Íntimamente ligada a las condiciones de vida de la gente, la construcción de ciudadanía desde la EA se enfoca a la construcción de pensamiento crítico y reflexivo sobre todos los aspectos que determinan el modo de vivir, habitar el mundo, construir sociedad en el marco de la democracia, que incluye comprender que la sociedad es un espacio donde muchas lógicas e intereses y culturas, en desiguales condiciones, disputan por hacer prevalecer diferentes puntos de vista y maneras de actuar. Se trata también, sin duda, de poder entender y discriminar entre intereses particulares y colectivos de desiguales proporciones. Por ello, además de ser la crisis ambiental resultado del modo en que comprendemos y habitamos el mundo, es también fruto del inequitativo modo en que se distribuyen los bienes ambientales. Hernández del Águila, en un texto denominado "La crisis Ecológica" (1985) sostiene en 
ese sentido que la degradación del medio natural y la degradación del medio social son dos manifestaciones de un mismo problema.

De este modo, la crisis ambiental es resultado de la injusticia distributiva producto de una lógica desigual de apropiación entre sectores dominantes y sectores subalternos y de la forma expoliativa y depredatoria en que nos relacionamos con la naturaleza. Por ende, no hay que olvidar que los impactos recaerán siempre de forma desproporcionada según la posición social de los colectivos que recibirán el efecto. Con esta definición le damos entrada a otro de los ejes que nos proponemos abordar: los temas o problemas ambientales como "conflictos ecológicos distributivos"; una conceptualización que proviene desde la economía ecológica. Desde este abordaje es clave desentrañar quiénes son los actores que intervienen en el conflicto, qué lenguajes de valoración del bien que disputan utilizan y cuáles son las formas organizativas desde donde los actores participan.

Desde la economía ecológica, Joan Martínez Alier (2001) (2004) (2007) asume sin lugar a dudas, que hay quienes se benefician más del crecimiento económico, mientras otros sufren los mayores costos del mismo. Parece obvio, pero producto de ésta desproporción en los beneficios se genera una "injusticia distributiva" que involucra los bienes naturales o aquellos que frecuentemente son conceptualizados como recursos o materias primas desde la economía convencional, por los cuales "nadie" paga: ¿quién paga por el aire, el agua que se usa en los procesos productivos?, ¿quién paga más allá del valor de mercado del extraído, el costo ambiental residual del proceso minero?, si pudiéramos calcular en términos monetarios el valor de un bosque, un paisaje o una especie ¿quién estaría dispuesto a pagar por el costo de su destrucción o de un aprovechamiento intensivo?.

El daño ecológico y el agotamiento de los bienes naturales se pueden valorar en dinero o en términos de existencia física, la pregunta de la economía ecológica es: si en cualquier conflicto todas las valoraciones pueden ser reducidas a la dimensión económica? Está claro que los precios de mercado, es decir el cálculo exclusivamente crematístico como lo llama el propio Martínez Allier, no reflejan ni el valor material real, ni el valor simbólico de los bienes naturales. De aquí que esta desigualdad lleva a un tipo de disputa por esos bienes, que el mencionado autor llama "conflictos ecológicos distributivos" o "conflictos de justicia ambiental", que involucra valoraciones económicas, pero también culturales. Esas valoraciones se expresan en significados y formas de enunciación.

Es decir, la forma en que estos conflictos por los bienes naturales se enuncian, expresan distintos lenguajes de valoración de los bienes en disputa. Así los perjudicados pueden pedir la internalización de las externalidades y una indemnización en dinero, pueden argumentar que el ambiente tiene gran valor ecológicos o paisajístico, que la tierra es sagrada, que los recursos de 
ese territorio están excluidos del mercado por acuerdos internacionales que los protegen y apelar a la defensa de los derechos humanos o los derechos colectivos (o bien utilizar varios de estos lenguajes de valoración en simultáneo) [8]. En medio de un conflicto ecológico, sostiene Martínez Alier (2001) (2004) la pregunta siempre será ¿quién tiene o quién se arroga el poder de determinar cuáles son los lenguajes de valoración pertinente? En este sentido, es importante señalar que desde esta disciplina (híbrida) se problematiza la posibilidad de hacer mensurables los daños ecológicos y el agotamiento de los recursos; se rechaza la simplificación de la complejidad y se acepta en cambio, la inconmensurabilidad de los valores.

\section{Precisando los objetivos pedagógicos}

Antes de entrar en cada uno de los objetivos, es necesario aclarar que los mismos ordenan los ejes de trabajo desde donde se desarrollarán los distintos módulos. Esos módulos están orientados por principios o valores, en el sentido axiológico del término y se presentan en base a los distintos enfoques que fuimos incorporando en esta propuesta:

Objetivo 1: transmitir la complejidad de las relaciones sociedad naturaleza desde la educación ambiental y apoyar la búsqueda de un enfoque integrativo de la ciencias naturales y sociales

- Eje de trabajo del Objetivo 1: la interdependencia de las ciencias y de la relación sociedad naturaleza.

- Principio Orientador: la interdependencia

Objetivo 2: Coadyuvar a transformar la comprensión de las relaciones sociedad/naturaleza desde un componente fuertemente ético

- Eje de trabajo del Objetivo 2: cambio de percepción de las relaciones sociedad/naturaleza.

- Principios Orientadores: justicia, cooperación, solidaridad ecológica.

Objetivo 3: Abordar los problemas ambientales como conflictos ecológicos distributivos

- Eje de trabajo del Objetivo 3: disputa por los bienes naturales: actores, lenguajes de valoración y organización

- Principio Orientador: inconmensurabilidad de los valores de los bienes naturales

\section{Hacia una definición de la propuesta didáctica La Educación ambiental y las TIC en contexto}

Con base en este marco teórico establecemos algunas líneas orientativas tendientes a identificar cuándo y porqué un contenido, tema o problema vinculado con la ciencia y/o con las dinámicas sociales e históricas deviene en 
conflicto ambiental, y por tanto es susceptible de trabajarse desde un enfoque de EA, cómo establecerlo y cómo tramitar su abordaje pedagógico. Y desde allí, proponer cómo se pueden articular las TICs para cumplir con nuestro propósito.

Lo primero es recordar que según se ha propuesto en este marco teórico, la hibridación disciplinar, y en ciertas circunstancias el diálogo de saberes, vienen creciendo como estrategias más adecuadas en contextos de incertidumbre creciente para la comprensión y la solución de los temas contemporáneos, pero sobre todo cuando el problema o conflicto por su propia complejidad induce a la búsqueda (o creación) de enfoques integradores, no como un procedimiento autoconsciente, sino de una manera espontánea, tal como señalara la literatura ya citada. En el campo educativo no es diferente, de hecho, prevalece una lógica que, las más de las veces, tiende a crear en torno a los temas ambientales nuevas especialidades (9).

De ahí, que nos propongamos abordar los temas o problemas ambientales en tres planos o ejes de trabajo que responde a nuestros tres objetivos:

- Como desafío a la comprensión de los saberes disciplinares y como campo de enfoques integrativos (principio de interdependencia de las ciencias)

- Como problema de corte ético que exige un cambio de percepción de la relación sociedad y naturaleza (principio de justicia, cooperación, solidaridad ecológica)

- Como conflicto ecológico distributivo (principio de inconmensurabilidad de valores)

Desde la perspectiva que se ha planteado entonces, el trabajo de la EA será el sugerir y provocar, hibridaciones conceptuales que nos permiten formalizarla como un enfoque no sólo teórico sino pedagógico-didáctico, de ciertos temas que involucran aspectos múltiples de la relación entre los grupos humanos y la naturaleza, socialmente significativos para los estudiantes y los educadores, en un contexto contemporáneo global y local, lo que equivale a hablar de y practicar- si no la interdisciplina- por lo menos una transversalidad colaborativa entendida como conocimiento transversal, o como gustaría decir Morin, promover una inteligencia apta para referirse de manera multidimensional a lo complejo. Ello implica una transformación que lejos de limitarse a lo programático tiende a lo paradigmático:

(...) Hay una inadecuación cada vez mas amplia profunda y grave, por una lado entre nuestros saberes desunidos divididos, compartimentados $y$, por otro realidades o problemas cada vez mas polidisciplinarios, transversales, multidimensionales, transnacionales, globales, planetarios. En esta inadecuación devienen invisibles: el contexto, lo global, lo multidimensional y lo complejo" (Morin, 1999, p. 15). 
Es tarea primaria de la EA hacerlas visibles. Adicionalmente la toma de decisiones, aspecto siempre conflictivo y urgente de lo contemporáneo, requiere la puesta en diálogo de diferentes saberes, para primero comprender y luego adoptar decisiones democráticas. Un conocimiento pertinente sólo es posible recuperando las mencionadas dimensiones invisibilizadas. Así, la EA se instala como disciplina híbrida en este nudo epistemológico, pedagógico y ético y desde allí se propone re-orientar a favor de una comprensión diferente y compleja de la relación sociedad/naturaleza. Este proceso de actualización educativa supone entre otros instrumentos la introducción de la TICs mediante la capacitación docente.

Evidentemente el uso o articulación de las TICs en EA, implica la incorporación de estas nuevas tecnologías al proceso mismo de enseñar el conocimiento complejo, en tanto herramientas facilitadoras de la revelación y comprensión de esa complejidad. No podría ser de otra manera, ya que las nuevas tecnologías de la información y comunicación forman parte ineludible del instrumental educativo necesario para transmitir eficazmente y asumir con autonomía la herencia cultural de la época, o al menos una parte significativa de ella. Según Violeta Nuñez:

(...) el acceso a la TIC por parte de los profesionales de la educación tiene que operar como garantía de democratización. Se trata de restituir al sujeto de la educación un lugar protagónico en sus procesos de adquisición y consiguiente apropiación, transformación y uso de los saberes y conocimientos en juego en cada época... (Nuñez, 1999, p. 162).

Como ya hemos dicho, no son las TICs en sí mismas lo mas importante, sino el desarrollo de una capacidad humana (social) para ponerlas al servicio de un mundo mejor, restituir un lugar protagónico al sujeto educativo supone ponerlo delante de las TiCs, no atrás. Es decir considerarlo más importante, dotarlo no sólo de la capacidad de uso, sino de la comprensión que le permita dominarlas para dejar de ser dominado. Creemos que la irrupción de las TIC -a una velocidad superior a la capacidad de adaptación y apropiación por parte de los potenciales usuarios en las distintas áreas de conocimiento- en un contexto de crisis civilizatoria producto de la irrupción de la problemática ambiental a nivel global y local, representa efectivamente un riesgo de profundización de la misma, tanto como una oportunidad para integrar estas herramientas tecnológicas al proceso de construcción de una nueva mirada.

Es decir, la velocidad con que las TICs se expanden puede ser muy útil para apoyar a la EA en la búsqueda del urgente cambio de percepción y comprensión de las relaciones sociedad-naturaleza. La ampliación de los horizontes de comprensión y participación, la horizontalización y el trabajo en red que estos nuevos recursos están generando marcarán definitivamente la forma de 
aprehender nuestro mundo y de crear e interactuar. La idea es que ese proceso no cierre sobre sí mismo, sino que sirva para comprender mejor la complejidad de la naturaleza y de la sociedad y de sus interacciones recíprocas.

(...) En el nuevo siglo, dominado por los entornos electrónicos, el desafío que afrontamos es crear nuevas oportunidades para tratar con nuestros semejantes en comunidades geográficas [porque] despojada de su contexto geográfico, la expresión cultural se convierte en la sombra de una experiencia integral, necesitamos por tanto prestar al menos tanta atención a la geografía y a la participación en auténticas comunidades, como al ciberespacio y al chat en una red de ordenadores. (Rifkin. 2000, p. 107).

La EA supone precisamente, una reconexión con los escenarios donde ocurren e interactúan procesos naturales, económicos, productivos y culturales. Espacios "concretos" donde la relación sociedades naturaleza se modela día a día, espacios de conflicto y de luchas de poder.

\section{La propuesta didáctica. Hacia algunas precisiones}

En esta perspectiva, la EA va siendo parte de la construcción de un campo disciplinar heterodoxo e híbrido, de ahí que sean muchos los temas que le pueden concernir. Sin embargo, en modo alguno compite, obstruye o reniega de los enfoques y abordajes propios de las disciplinas. El punto, es la posibilidad que ofrece este enfoque propuesto para identificar, estudiar, comprender y trabajar pedagógicamente las interrelaciones, multidimencionales y recíprocas que la sociedad humana establece con la naturaleza, como la posibilidad de encontrar un sentido apropiado a la articulación con las TICs en función de esta finalidad.

Vayámonos hacia algunas de las preguntas planteadas ¿Cuáles son o podrían ser los temas ambientales? ¿Cómo establecer que un asunto, una información o un contenido pueden ser tema de trabajo de la EA? ¿El que lo sea, excluye otros enfoques?

Al momento de establecer qué condiciones debe reunir un asunto para considerarlo un "tema de la EA", se debe tener cuenta que el "tema" puede:

- desafiar la comprensión de saberes disciplinares

- dar cuenta de un problema de corte ético que exige un cambio de percepción

- presentarse como un conflicto ecológico distributivo

- exigir una decisión expedita

- exhibir una combinación de algunos o todos estos tópicos

Estos criterios tienen validez tanto para temas surgidos de la realidad cotidiana de los lugares que habitamos (en la zona rural, en una pequeña localidad, en una ciudad grande o mediana; en la llanura, en la meseta, en la 
montaña, en la costa, o en la frontera), como para temas ya incluidos en los contenidos de la enseñanza.

Por ejemplo:

- el cambio climático

- la biodiversidad

- "la valorización de las bases naturales, y el poblamiento"

- "los ambientes naturales y su situación actual"

- la energía, energías renovables

- residuos sólidos urbanos

- importancia de la tecnología en los procesos de globalización

- "las industrias extractivas y su significado en el desarrollo histórico de América latina"

- el ambientalismo en Argentina

- conflictos territoriales entre campesinos e indígenas en la selva amazónica

- importancia del agua en los sistemas terrestres

Los anteriores son títulos o formulaciones de temas que reúnen las condiciones descriptas y que pueden convertirse en problema de estudio y reflexión multi o interdisciplinar. Ello no quita que también pueden ser abordados en forma parcial y/o profundizar en ellos una perspectiva particular desde otras áreas específicas del conocimiento, de hecho suele ocurrir al revés; pero el desafío de lo interdisciplinar radica, por lo menos, en la posibilidad de volver a reunir los recortes en una perspectiva de comprensión amplia y compleja.

Modelando el guión didáctico de EA con TICs dirigido a los docentes (10)

El despliegue de herramientas TIC's en la escuela, puede aportar no sólo recursos discursivos enriquecidos con imágenes, o directamente visuales, la posibilidad de modelizar situaciones complejas y participar interactivamente en ellas, sino que fundamentalmente pueden invitar al desarrollo de un pensamiento sistémico y práctico. Pudiendo, al dar cabida a saberes, interpretaciones y estímulos diversos, mediar entre el racionalismo extremo y el saber popular, el saber académico y el sentido común, como modos distintos de inteligir el mundo, pueden en definitiva, ayudar en el campo educativo, a revisar valores y construir otros sentidos.

Específicamente en relación con la promoción del uso de TICs por medio de las netbooks en la escuela secundaria pública, la presente propuesta didáctica dirigida a docentes, incluye como experiencia de innovación un itinerario didáctico organizado en tres instancias:

1. En la primera, se propone la construcción de un dispositivo visual simple destinado a introducir a los docentes en algunos principios e implicancias de la complejidad y su traducción al ejercicio transversal del conocimiento y la enseñanza. Esta etapa se resuelve recurriendo a 
producciones audiovisuales de diferente género, que permiten comunicar ideas con apoyo de imágenes y facilitar la fijación de conceptos que de otro modo resultarán arduos.

2. En la segunda instancia, se propone construir un guión didáctico de EA, una guía de cuestiones orientativas para abordar temas de EA en la escuela, que facilite a los docentes la confluencia disciplinar. Por ahora, se presenta un incipiente punteo que pretende a posteriori conformar los lineamientos básicos necesarios para un guión didáctico aplicable al abordaje de cualquier tema ambiental. El mismo se orienta según los tres objetivos de la propuesta, sus respectivos ejes de trabajo y principios. El guión didáctico aporta, por ende, una herramienta teórico-práctica para la problematización de temas ambientales:

\section{Guión didáctico de la EA (Propuesta Preliminar)}

Desafío didáctico: Cómo convertir un tema o contenido curricular relativo al ambiente en un problema de estudio, de reflexión transversal y en aprendizaje activo.

Horizonte Didáctico: Los temas de la educación ambiental, que pueden o no ser contenidos curriculares deben ser problematizados siempre desde diferentes enfoques, para ser comprendidos en toda la complejidad de sus dimensiones. En este horizonte didáctico deben estar presentes los tres ejes de trabajo a través de los principios de la interdependencia, el principio de la inconmensurabilidad de los valores de la naturaleza y los principios de la ética ecológica (justicia ecológica, solidaridad ecológica y cooperación ecológica).

\section{Pasos}

1. Adecuar el enfoque al nivel educativo mediante estrategias didácticas ajustadas conforme a la edad de los estudiantes y/o su circunstancia educativa.

2. Ubicarlos en el tiempo y en el espacio (regionalizar, localizar; territorializar). Se utiliza Google Earth como herramienta. (Atender a las funciones del programa, recorrer el menú que ofrece)

3. Trabajar la o las escalas en que se presenta.

4. Historizarlos. Se consultan distintas páginas Webs para rastrear conflictos ambientales.

5. Tratarlos interdisciplinariamente, solicitar siempre la concurrencia de otras miradas del conocimiento (principalmente otros docentes o 
gente que comunique saberes y experiencias no escolares) que lo complejicen y complementen su comprensión.

6. Tratar de vincular unos temas con otros en todos los sentidos posibles, destacando las diferencias de objetivos y enfoques disciplinares, pero rompiendo las barreras reflexivas (de los enfoques disciplinares) para construir una mirada integral y compleja.

7. Se sintetiza lo trabajado hasta el momento mapeando las categorías claves en CMAP como herramienta del docente para usar con los estudiantes (atender a las funciones del programa, recorrer el menús que ofrece)

8. Promover una simultaneidad coordinada y coherente del tratamiento del tema en diferentes áreas educativas

9. Relacionarlos todo lo posible con los contenidos presentes en el currículum.

10. Identificar actores sociales en la temática o problema ambiental.

11. Descubrir qué valores están involucrados en la cuestión y trabajar con ellos (Identificar los enunciados centrales con que los actores refieren al problema ambiental. Por ejemplo: hablan del agua de un río como elemento necesario para la vida? Hablan del río como bien paisajístico? Hablan de los derechos que tienen sobre el río? Lo ven como un recurso económico? Contemplan otras especies que dependen del río?

12. Tener en cuenta y compartir diferentes percepciones y concepciones sobre el río, en este caso.

13. Identificar el tipo de acciones que llevan a cabo los actores en defensa de sus intereses (iniciaron acciones legales? ¿Llevaron a cabo acciones directas? Es decir: ¿Se movilizaron o qué otras estrategias usaron?

14. Visita a la página http://iconoclasistas.com.ar/. Se la recorre con los participantes para conocer distintos recursos para mapear colectivamente conflictos. Se Proponer un ejercicio de mapeo.

15. Si fuera un conflicto local, se puede habilitar posteriormente la posibilidad que los estudiantes entrevisten a los actores involucrados, vecinos, o personas cercanas que les puedan dar información sobre el conflicto. Se Proponer un ejercicio de mapeo local de un conflicto ambiental.

16. Realizar siempre un manejo crítico de la información. 
17. Profundizar la conexión y hacerla lo más explícita posible entre las propuestas de trabajo áulico y las situaciones problemáticas del entorno, la región y localidad.

18. Trabajar los aspectos éticos que subyacen a las controversias representadas por conflictos ambientales.

19. Finalmente para sintetizar y exponer en forma integral el análisis del conflicto ambiental, es posible recurrir a diversos programas que permiten reunir toda la información obtenida y presentarla de manera clara y sintética con el apoyo de imágenes, mapas, gráficos, fotos, animación, etc.(atender a las funciones de los programas elegidos y recorrer el menú que ofrece).

3. En tercera instancia proponemos incorporar al itinerario didáctico, un recurso primordialmente lúdico. La razón radica en que la complejidad misma de los "temas ambientales" invita a reflexionar jugando, pues el número de faces, variables, miradas, actores que generalmente están involucrados supone variabilidad, diversidad y un grado de imprevisibilidad que junto a la densidad y conflictividad implicada en cada problemática, demandan estrategias didácticas abarcativas y flexibles capaces de recrear y procesar el conflicto mismo, que no son habituales en los duros recortes de las miradas curriculares y las estrategias didácticas convencionales. En este sentido el juego puede convertirse en estrategia complementaria directamente enfocada a la compresión y responder mejor al desafío de revelar la complejidad inherente de estas problemáticas. Muchos juegos pueden tener versiones físicas y versiones digitales que, lógicamente, no son excluyentes.

La finalidad del juego es divertirse y por tanto esa es su principal recompensa, más si viene asociada a la comprensión y el aprendizaje. Jugar es aprender y en cualquier edad. He aquí una importante potencialidad del cruce de la EA con las TIC's, pues ellas favorecen especialmente la comprensión mediante el juego, complementando e integrando sin forzamientos una dimensión lúdica al aprendizaje. Según Jeremy Rifkin (2002) el juego comunica, crea lazos de cooperación, participación, confianza; permite imaginar y crear escenarios imaginarios o re-crear escenarios reales, vincularse, desvincularse y comprometerse sin peligro, poner a jugar los distintos saberes y el sentido común, los instintos y los prejuicios, el juego se resiste, cómo la naturaleza o los valores a la impronta cartesiana y en esa medida constituye un espacio y un momento 
pleno de comprehensión y aprendizaje. Como dice Johan Huizinga, "la vida social es un inmenso juego" (Huizinga, en Riftin, 2002: 158).

Creemos que el diseño de propuestas didáctico-lúdicas apoyadas principalmente, aunque no únicamente, en recursos virtuales puede ser un camino propicio para facilitar la comprensión que se propone. Tales propuestas deberán diseñarse para convertirse en un recurso de disponibilidad corriente y articularse eficazmente con la utilización de programas y máquinas con que cuentan docentes y estudiantes.

En lo que sigue desarrollamos también en forma preliminarmente un ejemplo: El juego de rol. Los juegos de rol y simulación pueden ser una herramienta para abordar la complejidad de los temas ambientales en el ámbito escolar. El rol es la representación de un personaje con características propias que hay que interpretar. El juego es una actividad dirigida al disfrute de los participantes. Una buena partida de rol es jugar sin supeditar lo uno a lo otro. En este caso, los participantes forman un equipo y no compiten unos contra otros, se sustituye la competición por la colaboración (o negociación). Los jugadores tienen una misión común que entre todos deberán llevar a buen puerto.

Esta misión será propuesta por otro jugador, el docente, quién será un "director de juego", planteará y describirá las diferentes situaciones de la aventura (que previamente a preparado y estará ambientada en el contexto de la temática que quiera tratar en clase). De esta manera, el juego será por un lado, el diálogo entre los estudiantes y el docente, por otro la herramienta que el docente utilice para introducir a los estudiantes en el mundo donde los personajes, por ellos creados, viven; el contexto. El proceso se dará poco a poco, desafío tras desafío. La estrategia se presentará en forma de breves juegos en la computadora, videos e imágenes y consultas de material de lectura, para poder resolver los enigmas y conflictos y así proseguir a un siguiente nivel. La idea general es que los estudiantes armen cada uno un personaje con sus características propias, sus virtudes y sus debilidades, sus carencias y sus recursos, creencias y conocimientos.

Se trata de un juego donde no existen ganadores ni perdedores. Decisiones diferentes conducen a resultados (provisorios) distintos. Sólo desarrollando su creatividad ante los desafíos que se le presenten, es que obtendrán los resultados que logren, la supervivencia y el beneficio del grupo. No es la finalidad hallar soluciones, sí aportar elementos para el trabajo, la discusión, el análisis y la comprensión. En todos los casos los juegos pondrán en valor todos o algunos de los principios que orientan cada objetivo y eje de trabajo de la EA (principio de interdependencia) (principios de justicia, cooperación solidaridad ecológica) (principio de inconmensurabilidad de valores).

Otros juegos posibles a desarrollar podrían ser:

- juegos de recorrido más sencillos, son breves con pocos elementos y pocas reglas, orientados a facilitar abordajes desde lo disciplinar, 
- Juegos de competición, de táctica y estrategia, se proponen o demandan respuestas desde diferentes ciencias o diferentes saberes,

- juegos omniscientes de administración y de gestión, donde sólo mueven las piezas sin compromiso con el conflicto,

- juegos de diseño personal o grupal o modelizaciones

- juegos colaborativos y de rol, en otras variantes, donde los participantes están comprometidos y son parte de un conflicto ecológico, deben tomar decisiones que afectan la relación con la naturaleza y el equilibro ecológico en general.

Para cerrar, esta propuesta didáctica de EA en su articulación con recursos TIC's, se compone de estas tres instancias:

(i) un audiovisual para apoyar la comunicación de aspectos conceptuales sobre los temas y sobre el enfoque.

(ii) un guión didáctico destinado a orientar el abordaje de cualquier "tema ambiental".

(iii) un menú de juegos digitales destinados a recrear, e involucrar a los participantes desde diferentes lugares y posibilidades, en escenarios de conflicto ambiental, controversia científica, confrontación de valores y saberes, de manera tal que puedan, mediante un ejercicio lúdico, modificar su percepción y su comprensión a partir del compromiso con una situación determinada.

\section{A modo de cierre y de síntesis}

El presente artículo no tiene una conclusión. Y no podría tenerla porque en su horizonte estuvo el propósito de generar -aunque incipiente- una propuesta de capacitación docente que articulara EA y TIC's. Para ello se pretendió delinear en primer lugar, una dirección conceptual-metodológica que permitiera establecer el enfoque desde dónde avanzar. En segundo lugar, establecer una batería de objetivos interrelacionados que oriente los ejes temáticos de la propuesta y finalmente, una didáctica de trabajo que pudiera operar como un ejercicio posible a la hora de relacionar EA y TICs en la escuela. En lo que respecta específicamente a la propuesta didáctica se trabajó sobre tres instancias concretas mencionadas anteriormente y que en la actualidad están en distintos grado de avance:

(i) un audiovisual para apoyar la comunicación de aspectos conceptuales sobre los temas y sobre el enfoque.

(ii) un guión didáctico destinado a orientar el abordaje de cualquier "tema ambiental".

(iii) un menú de juegos digitales destinados a recrear, e involucrar a los participantes desde diferentes lugares y posibilidades, en escenarios 
de conflicto ambiental, controversia científica, confrontación de valores y saberes.

De esta forma, las tres instancias conforman un único dispositivo que creemos puede servir como esquema general de trabajo tanto en la capacitación dirigida a docentes, como en las clases que estos último puedan dirigir a sus estudiantes de escuelas medias.

Es indudable que los problemas ambientales se han traducido en las aulas en "desafíos de comprensión". También es indudable que las Tic's ofrecen la posibilidad de otras formas de inteligir el universo natural y social. De este modo, los problemas ambientales, como las Tic's "desafían" la forma en que los científicos y profesores hemos sido formados, de ahí la necesidad de explorar y definir enfoques capaces de procesar la creciente complejidad del mundo, establecer objetivos pasibles de alcanzarse sin desentender esas complejidades y generar propuestas didácticas adaptables y flexibles no sólo a las nuevas problemáticas sino también, a todas aquellas que, sin ser nuevas, es posible actualmente comprenderlas de forma más sistémica. He aquí la importancias de generar esfuerzos orientados a elaborar propuestas de articulación de EA y Tic's como un campo transversal de formación docente que permita la confluencia de perspectivas para tramitar pedagógicamente la complejidad inherente al contexto descrito e inaugurar una mirada híbrida e interdisciplinar en el abordaje de temas ambientales en los distintos escenarios educativos.

\section{Notas Bibliográficas}

(1) Este trabajo surge como respuesta a la solicitud de sumar una mirada ambiental en la experiencia de formación docente referida a las TIC's que lleva a cabo el Programa Escuelas de Innovación como parte del Programa-política "Conectar Igualdad", del gobierno argentino, que ha repartido millones de netbooks a docentes y alumnos de escuelas públicas.

(2) Ciertamente la escuela como dispositivo central, eficaz, excluyente y hegemónico en la transmisión/reproducción del patrimonio cultural representado por el conocimiento, e incluso en su aptitud generadora de subjetividad (lo que incluye el rol y la formación del docente en tanto su agente principal) es desde hace décadas objeto de dudas y cuestionamientos tanto en sus aspectos formales como en lo referido a los contenidos curriculares, pero probablemente sean, en dos planos diferentes pero sensiblemente conectados, las nuevas Tic's y el problema de la relación sociedad/naturaleza, los aspectos en los cuales el dispositivo escolar evidencia un analfabetismo que marca un hiato difícil de sortear, considerando la velocidad de los cambios en estos aspectos mencionados, lo cual la aleja cada vez más de aquella centralidad y de la potencialidad de ser agente germinador de utopías sustentables.

(3) De manera general, un conocimiento significativo en el marco del constructivismo, refiere básicamente a aquel que pueda articularse coherentemente con los conocimientos previos que se poseen, "anclarse" satisfactoriamente mediante la comprensión en la estructura informativa y cognitiva previa del sujeto, ser estructurante en el sentido de dar lugar a nuevas posibilidades de conocimiento e intelección. Supone la conciencia 
de la meta cognición y requiere contextualización, es decir estar referido y conectado con los procesos vitales y cotidianos de la vida de los individuos y la sociedad.

(4) Entre los referentes en el campo ambiental se pueden mencionar a Carlos Jesús Delgado Díaz, Edgar Morin, Enrique Leff, Carlos Galano, Edgar Gonzalez Gaudiano, Lucie Sauvé, Nicolás Sosa, Víctor Toledo entre otros.

(5) En el citado cuadro la hibridación disciplinar resulta de combinar el enfoque de la ecología (un enfoque inherentemente sistémico) con los de otras disciplinas del campo social o humanístico.

(6) Respecto a la particular configuración histórica de la EA en América latina se puede ver Edgar González Gaudiano (2007) "Educación ambiental: trayectorias, rasgos y escenarios”. Crefal-UANL-Plaza y Valdez México.

(7) Respecto al enfoque de construcción de ciudadanía específicamente consultar el diseño para la secundaria bonaerense creado con la intención explícita de incorporar miradas transversales e interdisciplinares "La educación ambiental y la construcción de ciudadanía: un espacio para la articulación de saberes y acciones". En DGEPBA (2007) Diseño Curricular para la ES Construcción de Ciudadanía, (pp. 59 -67). Disponible en la Página Web: http://abc.gov.ar/lainstitucion/organismos/consejogeneral/disenioscurriculares/ documentosdescarga/secundariaciudadania.pdf. Respecto al rol de la sociedad civil en la conformación de un campo de la EA en Argentina, se puede consultar es el documento elaborado por Pablo Sessano (2010) "Educación ambientalistas ambiental y educación ambiental no formal en argentina, entre el marketing, la ausencia pública y las organizaciones sociales". Disponible en www.copeaargentina.com.ar/UBACYT. También puede consultarse del mismo autor "Educación ambiental y pedagogías emancipadoras". En Revista Eletrônica em Gestão, Educação e Tecnología Ambiental REGET-CT/UFSM. 3, (3) 352-360 Disponible en Pagina Web: http://cascavel.ufsm.br/revistas/ojs-2.2.2/index. $\mathrm{php} / \mathrm{reget} / \mathrm{article} / \mathrm{view} / 3300 / 1818$. Respecto a la definición de la crisis ambiental como crisis social se puede consultar el Manifiesto por la Vida. (2002). El mismo surgió como producto del Simposio sobre Ética y Desarrollo Sustentable, desarrollado en Bogotá, Colombia en el mes Mayo de 2002, al que asistieron intelectuales y militantes latinoamericanos comprometidos con la educación y el ambiente.

(8) La región latinoamericana está en la actualidad atravesada por varios ecológicos distributivos. Entre ellos se incluyen aquellos conflictos originados en las antiguas reivindicaciones de tierra y territorio de las comunidades indígenas. Para observar la aplicación en simultáneo de varios lenguajes de enunciación sobre estas reivindicaciones se puede ver la ponencia de Silvina Corbetta (2012) "Las demandas de los pueblos indígenas al Estado en el contexto de los conflictos socioambientales regionales", VII Jornadas de Sociología 2012, Universidad Nacional de General Sarmiento, Polvorines, Pcia. Bs. As. Argentina, del 24 al 25 de Abril de 2012.

(9) Últimamente han surgido nuevos programas educativos que incluyen etapas o fragmentos de programas de disciplinas consolidadas en un intento por crear un perfil profesional y técnico con una mirada más amplia sobre los temas ambientales. No responden sin embargo, al modelo de disciplina híbrida que hemos mencionado, pues mantienen sus enfoques muy alejados todavía de la perspectiva de las ciencias sociales, orientan sus objetivos a un nicho laboral técnico relativamente especializado y omiten la complejidad en la articulación temática interna.

(10) Debe tenerse en cuenta que las ideas y propuestas presentadas en este articulo, especialmente a partir de este acápite, se encuentran en estado de experimentación constituyendo una primer aproximación a la integración transversal de la Educación Ambiental al proceso de actualización de la formación en las nuevas tecnologías de la información y comunicación para uso en la escuela. Hay muchos recursos disponibles en forma de 
software ya sean juegos o utilidades que pueden servir para esta integración, sin embargo como no se trata de agregar simplemente estos recursos, sino de articularlos en una lógica de abordaje transversal de temas ambientales, que favorezca la ampliación de las perspectivas sobre los mismos y desde las áreas y disciplinas; se entiende que los recursos Tic's no solo están al servicio de la comprensión temática, sino más que nada, al de una integración de las miradas y los abordajes. Ambas cuestiones, de contenido y de métodos, forman parte de la problematización que es necesario enfatizar en el cruce que se propone. Asumimos que ello requiere un trabajo específico tendiente a analizar y juzgar la pertinencia de los recursos disponibles para tal fin.

\section{Referencias Bibliografías}

- Capra, F. (2007). "La ciencia física es la base de una vida sostenible". Revista CERN Courrier. Entrevista realizada por Beatrice Bressan. Centro Europeo de Investigación Nuclear (CERN) Mayo (pp. 15). Disponible en la Página Web: http://www.tendencias21. net/Fritjof-Capra-la-ciencia-fisica-es-la-base-de-una-vida-sostenible_a1577.html

- $\quad$ Corbetta, S., (2012) "Las demandas de los pueblos indígenas al Estado en el contexto de los conflictos socioambientales regionales". En VII Jornadas de Sociología 2012, Universidad Nacional de General Sarmiento, Polvorines, Pcia. Bs. As. Argentina, del 24 al 25 de Abril de 2012.

- DGEPBA (2007). "La educación ambiental y la construcción de ciudadanía: un espacio para la articulación de saberes y acciones". En Diseño Curricular para la ES: Construcción de Ciudadanía 1 a 3er. Año. (pp. 59 -67) La Plata.

- $\quad$ Funtowicz, S., y Ravetz J., (1993). Epistemología política, ciencia con la gente. Serie Fundamentos de las Ciencias del Hombre Nro.107. Buenos Aires: CEAL.

- $\quad$ Funtowicz, S., y Ravetz J., (2000). La Ciencia posnormal. Barcelona: Icaria.

- $\quad$ Funtowicz, S., Marchi, B., (2000) "Ciencias posnormal, complejidad reflexiva y sustentabilidad” en Leff, E., (2000) La complejidad Ambiental (pp.54-84). México: PNUMA-Siglo XXI.

- Gaudiano E. (2007). Educación ambiental: trayectorias, rasgos y escenarios. México: Crefal-UANL-Plaza y Valdez.

- García, R., (1994). "Interdisciplina y sistemas complejos”. En Leff. E. (comp). Ciencias Sociales y Educación Ambiental (pp. 85- 124). Barcelona: Gedisa.

- Hernández del Águila, R. (1985). La crisis Ecológica. Barcelona: Laia.

- Leff, E. (2002). Saber Ambiental. Sustentabilidad, racionalidad, complejidad, poder. Buenos Aires: Siglo XXI.

- Manifiesto por la Vida (2002). Por una Ética para la Sustentabilidad. Aportes para pensar la formación docente desde la formación ambiental. En CTERA-EMV (2004) Publicación, Simposio sobre Ética y Desarrollo Sustentable, Bogotá, Colombia, Mayo, 2002.

- Morín, E. (1999). Los siete saberes para la educación del futuro. Buenos Aires: UNESCONueva Visión.

- Morin, E. (1996). Introducción al pensamiento complejo. Barcelona: Gedisa.

- Martínez Allier, J. (2001). "Globalización y conflictos económicos-ecológicos. Justicia ambiental, sustentabilidad y valoración”. En Ecología Política, (21) Cuadernos de Debate Internacional, Barcelona: Icaria Editorial, Disponible en la Página Web: http://www. ecologiapolitica.info/ep/21.pdf

- Martínez Alier, J. (2004). El ecologismo de los pobres. Conflictos ambientales y lenguajes de valoración. Barcelona: Icaria Antrazyt-FLACSO. 
- Martínez Alier, J. (2007). "El Estado y la sociedad civil en los conflictos ambientales publicado" originalmente en el Nro. 13 de la revista ecuatoriana Entre Voces, septiembreoctubre y en Revista Pueblos, Disponible en la Página Web: http://www.ecoportal.net/ content/view/full/74513/

- $\quad$ Nuñez, V. (1999). Pedagogía social: cartas para navegar en el nuevo milenio. Buenos Aires: Santillana.

- Sessano, P. (2010). "Educación ambiental y educación ambiental no formal en argentina, entre el marketing, la ausencia pública y las organizaciones sociales". Disponible en la Página Web: www.copeaargentina.com.ar/UBACYT

- Sessano, P. (2011). "Educación ambiental y pedagogías emancipadoras". En Revista Eletrônica em Gestão, Educação e Tecnologia Ambiental. REGET-CT/UFSM. 3 (3), 352 - 360. Disponible en la Página Web: http://cascavel.ufsm.br/revistas/ojs-2.2.2/index. php/reget/article/view/3300/1818

- $\quad$ Sosa, N. (1991) "Ética Ecológica". En Los retos de una ética aplicada (pp. 477-499). Valencia: Iglesia Viva.

- Toledo, V., Alarcón Chaides, P. \& Barón, L. (2002). Revitalizar lo Rural: un enfoque socioecológico. En Gaceta Ecológica, Nro. 62, 7-20, DF, México: Instituto Nacional de Ecología.

- Rifkin, J. (2002). La era del acceso. La revolución de la nueva economía. Buenos Aires: Paidós.

- $\quad$ Aliacar, P., Fernandez, C.,Miami,S. y Saez,T.(1992) “¿Qué es un juego de rol?” En Guía del juego de rol. Buenos Aires: Ediciones Zinco. 